\title{
Financial Burdens of Out-of-Pocket Prescription Drug Expenditures under High-Deductible Health Plans
}

J Gen Intern Med 36(9):2903-5 DOI: $10.1007 / \mathrm{s} 11606-020-06226-\mathrm{x}$

(c) Society of General Internal Medicine (This is a U.S. government work and not under copyright protection in the U.S.; foreign copyright protection may apply) 2020

\section{INTRODUCTION}

The costs of prescription drugs increased significantly in the USA over the past few years. ${ }^{1}$ The prevalence of high-deductible health plans (HDHPs) also increased steadily over the last two decades. ${ }^{2}$ Since HDHP enrollees may face the full cost of their initial purchases of prescription drugs, increases in the prices of prescription drugs are likely to have a significant impact on HDHP enrollees. Prior research examined total out-of-pocket health care expenditure burdens of HDHP enrollees. ${ }^{3{ }^{4}}$ Little is known, however, about the burdens of out-of-pocket prescription drug expenditures in particular. This study examines financial burdens of out-of-pocket prescription drug expenditures across different levels of deductibles. The study focuses on low-income adults (family income less than $250 \%$ of Federal Poverty Level) with multiple, prevalent chronic conditions, who are more likely to be constrained by their resources and use more prescription drugs.

\section{METHODS}

Data for this analysis come from 2012-2017 Medical Expenditure Panel Survey Household Component (MEPS-HC). The sample was restricted to adults ages 19 to 64 who were enrolled in employer-sponsored health insurance plans throughout the year. Data was pooled across multiple years given the small sample size of the subpopulation of lowincome adults with multiple chronic conditions. The following self-reported chronic conditions were identified: Diabetes, asthma, hypertension, arthritis, heart disease, cancer, chronic bronchitis, stroke, and emphysema. Following the literature, financial burden of prescription drugs was calculated as annual family out-of-pocket prescription drug spending divided by annual family disposable (after-tax) income, and 10-percent burden (out-of-pocket prescription drug spending exceeding 10 percent of disposable income) was used as a measure of high burden. ${ }^{5}$ Health plans were classified into three

Received June 16, 2020

Accepted September 7, 2020

Published online September 18, 2020 categories - high-deductible (deductible levels exceeded the Internal Revenue Service threshold for high-deductible plans), low-deductible (deductibles were below the Internal Revenue Service threshold), and no-deductible health plans. Two-tailed $t$ tests were used for making comparisons.

\section{RESULTS}

Among all adults $(n=39,421)$, the prevalence of 10-percent prescription drug burden was $1.2 \%$ or lower for any deductible group (Table 1). Among low-income adults $(n=7,510)$, the prevalence of 10-percent burden for high- and low-deductible enrollees was $5.0 \%(p<.01)$ and $3.1 \%(p<.01)$, respectively, compared with $1.6 \%$ among no-deductible enrollees. Among low-income adults with two or more chronic conditions $(n=$ $1,354)$, the high burden rate for the high-deductible group, at $14.3 \%$, was higher than that for the no-deductible group at $5.5 \%(p<.05)$. Among low-income adults with multiple chronic conditions, high-deductible enrollees were more likely than the no-deductible enrollees to have a 10-percent burden from brand name drugs alone $(11.5 \%$ versus $3.2 \%, p<.05)$, but the differences in the prevalence of 10-percent burden from generic drugs alone across deductible groups were not statistically significant (Table 2).

\section{DISCUSSION}

Among low-income adults with employer-sponsored insurance who had multiple chronic conditions and were enrolled in high-deductible plans, about $14.3 \%$ had family out-ofpocket prescription drug expenditures exceeding 10 percent of family disposable income. While out-of-pocket costs for prescription drugs have decreased in recent years, ${ }^{1}$ the results of this study suggest that for low-income adults with multiple chronic conditions who are enrolled in employer-sponsored high-deductible plans, out-of-pocket prescription drug costs may still result in significant financial hardships. As brand name drugs tend to be expensive, it is not surprising that the differences in financial burdens across deductible levels are coming primarily from out-of-pocket spending on brand name drugs. The coronavirus pandemic may further exacerbate the financial burdens of prescription drugs in numerous ways. For example, utilization of prescription drugs for mental health may increase ${ }^{6}$, which may affect the out-of-pocket costs for those in high-deductible health plans in particular. Also, loss 
Table 1 Family Out-of-Pocket Prescription Drug Expenditure Burden among Adults Ages 19 to 64 with Employer-Sponsored Insurance ${ }^{\text {a }}$ 2012-2017

\begin{tabular}{|c|c|c|c|}
\hline Population subgroups & $\begin{array}{l}\text { High-deductible health } \\
\text { plan enrollees }\end{array}$ & $\begin{array}{l}\text { Low-deductible health } \\
\text { plan enrollees }\end{array}$ & $\begin{array}{l}\text { No-deductiblehealth plan } \\
\text { enrollees }{ }^{\dagger}\end{array}$ \\
\hline \multicolumn{4}{|l|}{ All adults $(n=39,421)$} \\
\hline Mean disposable family income $(2017 \$)^{\mathrm{b}}$ & $\begin{array}{l}80079^{*} \\
(77982 \text { to } 82175)\end{array}$ & $\begin{array}{l}75606 \\
\text { (74063 to } 77148)\end{array}$ & $\begin{array}{l}76452 \\
(73742 \text { to } 79161)\end{array}$ \\
\hline $\begin{array}{l}\text { Mean family out-of-pocket expenditures on prescrip- } \\
\text { tion drugs }(2017 \$)\end{array}$ & $\begin{array}{l}413 * * * \\
(370 \text { to } 455)\end{array}$ & $\begin{array}{l}315 \\
(295 \text { to } 335)\end{array}$ & $\begin{array}{l}293 \\
(255 \text { to } 331)\end{array}$ \\
\hline Adults with family out-of-pocket prescription drug & $1.2 *$ & & \\
\hline $\begin{array}{l}\text { expenditures }>10 \% \text { of income, } \% \\
\text { Low-income adults }{ }^{\mathrm{c}}(n=7.510)\end{array}$ & (0.9 to 1.5$)$ & $(0.6$ to 1.0$)$ & $(0.5$ to 1.0$)$ \\
\hline \multicolumn{4}{|l|}{ Low-income adults ${ }^{\mathrm{c}}(n=7,510)$} \\
\hline Mean disposable family income (2017 \$) & $\begin{array}{l}33949 \\
(32440 \text { to } 35457)\end{array}$ & $\begin{array}{l}32564 \\
(31762 \text { to } 33366)\end{array}$ & $\begin{array}{l}32957 \\
(31824 \text { to } 34090)\end{array}$ \\
\hline Mean family out-of-pocket expenditures on prescrip- & $420 * *$ & $297 *$ & 228 \\
\hline tion drugs $(2017 \$)$ & (308 to 533$)$ & (252 to 341$)$ & (181 to 276$)$ \\
\hline Adults with family out-of-pocket prescription drug & $5.0 * *$ & $3.1 * *$ & 1.6 \\
\hline expenditures $>10 \%$ of income, $\%$ & $(3.2$ to 6.8$)$ & $(2.3$ to 4.0$)$ & $(0.9$ to 2.4$)$ \\
\hline Mean disposable family income $(2017$ \$) & \multicolumn{2}{|c|}{ Low-income adults with two or more chronic conditions $(n=1,354)^{\mathrm{d}}$} & \\
\hline & (27162 to 32111$)$ & (27218 to 30247$)$ & $(27047$ to 31850$)$ \\
\hline Mean family out-of-pocket expenditures on prescrip- & 1019 & 634 & 601 \\
\hline tion drugs $(2017 \$)$ & (641 to 1396$)$ & (534 to 734$)$ & (427 to 774 ) \\
\hline Adults with family out-of-pocket prescription drug & $14.3 *$ & 7.9 & 5.5 \\
\hline expenditures $>10 \%$ of income, $\%$ & (8.3 to 20.4$)$ & (4.7 to 11.0$)$ & $(2.6$ to 8.4$)$ \\
\hline
\end{tabular}

Source: Author's calculation from the Medical expenditure Panel Survey Household Component (MEPS HC), 2012-2017. The estimates were population-weighted. The standard errors were adjusted for the complex design of the MEPS. The 95\% confidence intervals are in parentheses. All dollar values were adjusted to 2017 dollars using the Consumer Price Index for All Urban Consumers (CPI-U)

${ }^{a}$ The sample is comprised of adults ages 19 to 64 who were enrolled in employer-sponsored health insurance plans and no other coverage throughout the year ${ }^{b}$ Family was defined as health insurance eligibility units (HIEUs), which comprised adults, their spouses, and co-residing children under 19. Disposable family income was defined as after-tax family income (Income taxes, Social Security taxes, and Medicare taxes were simulated using the web-based version of the National Bureau of Economic Research TAXSIM model)

${ }^{c}$ Family income $<250 \%$ of Federal Poverty Level

${ }^{d}$ Using the self-reported priority conditions in MEPS HC, the following diagnosed conditions were identified: Diabetes, asthma, hypertension, arthritis, heart disease, cancer, chronic bronchitis, stroke, and emphysema. Adults who reported having ever been diagnosed with coronary heart disease, angina, myocardial infarction, or any other kind of heart condition or heart disease were defined as having heart disease. Adults who reported having ever been diagnosed with asthma and who reported they still had asthma or had an asthma attack in the past 12 months were defined as having asthma. Adults who reported being diagnosed with high blood pressure on two or more occasions were defined as having hypertension

†ase group

$*, * * * * *$ Statistically significantly different, based on two-sample t tests, from the no-deductible plan enrollees at the $5 \%, 1 \%$, or $0.1 \%$, respectively

Table 2 Family Out-of-Pocket Burden of Brand Name and Generic Drug Expenditures among Low-Income Adults (Family Income < 250\% of FPL) Ages 19 to 64 with Employer-Sponsored Insurance and with Two or More Chronic Conditions, 2012-2017

\begin{tabular}{|c|c|c|c|}
\hline & $\begin{array}{l}\text { High-deductible health } \\
\text { plan enrollees }\end{array}$ & $\begin{array}{l}\text { Low-deductible health } \\
\text { plan enrollees }\end{array}$ & $\begin{array}{l}\text { No-deductible health plan } \\
\text { enrollees }^{\dagger}\end{array}$ \\
\hline $\begin{array}{l}\text { Mean disposable family income ( } 2017 \text { \$) (from } \\
\text { Table } 1)^{\mathrm{a}} \\
\text { Mean family out-of-pocket expenditure on brand name } \\
\text { drugs }(2017 \text { ) } \\
\text { Mean family out-of-pocket expenditure on generic drugs } \\
(2017 \$) \\
\text { Adults with family out-of-pocket brand name drug } \\
\text { expenditures }>10 \% \text { of income, } \% \\
\text { Adults with family out-of-pocket generic drug expendi- } \\
\text { tures }>10 \% \text { of income, } \%\end{array}$ & $\begin{array}{l}29636 \\
(27162 \text { to } 32111) \\
712^{*} \\
(405 \text { to } 1020) \\
306 \\
(212 \text { to } 401) \\
11.5^{*} \\
(5.6 \text { to } 17.4) \\
4.8 \\
(1.8 \text { to } 7.7)\end{array}$ & $\begin{array}{l}28732 \\
(27218 \text { to } 30247) \\
386 \\
(302 \text { to } 469) \\
248 \\
(214 \text { to } 282) \\
4.8 \\
(2.3 \text { to } 7.3) \\
3.8 \\
(1.6 \text { to } 6.0)\end{array}$ & $\begin{array}{l}29449 \\
(27047 \text { to } 31850) \\
352 \\
(195 \text { to } 509) \\
249 \\
(195 \text { to } 302) \\
3.2 \\
(0.9 \text { to } 5.5) \\
3.2 \\
(1.2 \text { to } 5.2)\end{array}$ \\
\hline
\end{tabular}

Source: Author's calculation from the Medical expenditure Panel Survey Household Component (MEPS HC), 2012-2017. The estimates were population-weighted. The standard errors were adjusted for the complex design of the MEPS. The 95\% confidence intervals are in parentheses. All dollar values were adjusted to 2017 dollars using the Consumer Price Index for All Urban Consumers (CPI-U)

The sample comprised adults ages 19 to 64 who were enrolled in employer-sponsored health insurance plans and no other coverage throughout the year

FPL, federal poverty level

Using the self-reported priority conditions in MEPS HC, the following diagnosed conditions were identified: Diabetes, asthma, hypertension, arthritis, heart diseases, cancer, chronic bronchitis, stroke, and emphysema. Adults who reported having ever been diagnosed with coronary heart disease, angina, myocardial infarction, or any other kind of heart condition or heart disease were defined as having heart disease. Adults who reported having ever been diagnosed with asthma and who reported they still had asthma or had an asthma attack in the past 12 months were defined as having asthma. Adults who reported being diagnosed with high blood pressure on two or more occasions were defined as having hypertension

Out-of-pocket expenditures on brand name drugs and generic drugs add up to total out-of-pocket prescription drugs expenditures

${ }^{a}$ Family was defined as health insurance eligibility units (HIEUs), which comprised adults, their spouses, and co-residing children under 19. Disposable family income was defined as after-tax family income (Income taxes, Social Security taxes, and Medicare taxes using the web-based version of the National Bureau of Economic Research TAXSIM model)

tBase group

*Statistically significantly different, based on two-sample t tests, from the no-deductible plan enrollees at the 5\% 
of jobs may not only change the composition of adults with access to employer-sponsored insurance but also reduce family income. The impact might be worse for those with chronic conditions as they could be at higher risk of developing serious illness from coronavirus. The estimates from this study can be used as a baseline to compare with later estimates, once data on household prescription drugs use and income during the pandemic becomes available. The key takeaway point of this paper for general internists is that for patients with chronic conditions, who are more likely to use prescription drugs, outof-pocket costs of prescription drugs could be really burdensome if they are enrolled in high-deductible plans.

Salam Abdus, Ph.D. ${ }^{1}$

${ }^{1}$ Division of Research \& Modeling, Center for Financing, Access, and Cost Trends, Agency for Healthcare Research \& Quality, Rockville, MD, USA

Corresponding Author: Salam Abdus, Ph.D.; Division of Research \& Modeling, Center for Financing, Access, and Cost Trends, Agency for Healthcare Research \& Quality, Rockville, MD, USA (e-mail: salam.abdus@ahrq.hhs.gov).

\section{Compliance with Ethical Standards:}

Conflict of Interest: The author has no conflict of interest.

Disclaimer: Any opinions and conclusions expressed herein are those of the author and do not necessarily represent the views of the Agency for Healthcare Research and Quality or the Department of Health and Human Services.

\section{REFERENCES}

1. IQVIA Institute for Human Data Science. Medicine use and spending in the U.S.: A review of 2017 and outlook to 2022. Parsippany, NJ: IQVIA Institute for Human Science; 2018. Available at: https://www.iqvia.com/ insights/the-iqvia-institute/reports/medicine-use-and-spending-in-theus-review-of-2017-outlook-to-2022. Accessed September 30, 2019.

2. Henry J. Kaiser Family Foundation and Health Research and Educational Trust, Employer Health Benefits Survey, 2017. Menlo Park, CA: KFF; 2017. https://www.kff.org/health-costs/report/2017-employer-healthbenefits-survey/. Accessed September 30, 2019.

3. Abdus S, Keenan P. Financial burden of employer-sponsored highdeductible health plans for low-income adults with chronic health conditions. JAMA Intern Med. 2018; 178(12): 1706-1708.

4. Segel JE, Kullgren JT. Health insurance deductibles and their associations with out-of-pocket spending and affordability barriers among us adults with chronic conditions. JAMA Intern Med. 2017; 177(3):433-436.

5. Gellad WF, Donohue JM, Zhao X, Zhang Y, Banthin JS. The financial burden from prescription drugs has declined recently for the nonelderly, although it's still high for many. Health Aff (Millwood). 2012; 31(2): 408416.

6. Minemyer P. Prescriptions for antidepressants, anti-anxiety, antiinsomnia drugs jumps $21 \%$ post COVID-19. Fierce Healthcare, 16, 2020. Retrieved from: https://www.fiercehealthcare.com/payer/express-scriptscovid-19-driving-up-use-behavioral-health-medications. Accessed 1 July 2020 .

Publisher's Note: Springer Nature remains neutral with regard to jurisdictional claims in published maps and institutional affiliations. 